\title{
Enhanced Mechanical Properties in 6082 Aluminum Alloy Processed by Cyclic Deformation
}

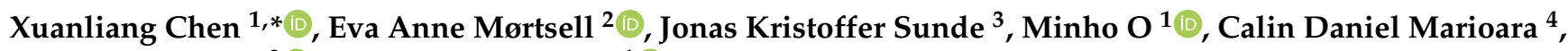 \\ Randi Holmestad ${ }^{3}$ and Equo Kobayashi ${ }^{1}$ (D) \\ 1 Department of Materials Science and Engineering, Tokyo Institute of Technology, 2-12-1-S8-18, Ookayama, \\ Meguro-ku, Tokyo 152-8552, Japan; o.m.aa@m.titech.ac.jp (M.O.); equo@mtl.titech.ac.jp (E.K.) \\ 2 Research and Technology Development, Hydro Aluminium, Romsdalsvegen 1, N-6601 Sunndalsøra, Norway; \\ Eva.Mortsell@hydro.com \\ 3 Department of Physics, Norwegian University of Science and Technology (NTNU), Høgskoleringen 5, \\ N-7491 Trondheim, Norway; jonas.sunde@hydro.com (J.K.S.); randi.holmestad@ntnu.no (R.H.) \\ 4 Materials and Nanotechnology, SINTEF Industry, Høgskoleringen 5, N-7465 Trondheim, Norway; \\ calin.d.marioara@sintef.no \\ * Correspondence: chen.x.af@m.titech.ac.jp; Tel.: +81-3-5734-3139
}

check for updates

Citation: Chen, X.; Mørtsell, E.A.; Sunde, J.K.; O, M.; Marioara, C.D.; Holmestad, R.; Kobayashi, E.

Enhanced Mechanical Properties in 6082 Aluminum Alloy Processed by Cyclic Deformation. Metals 2021, 11, 1735. https://doi.org/10.3390/ met11111735

Academic Editor: Babak Shalchi Amirkhiz

Received: 1 October 2021

Accepted: 28 October 2021

Published: 30 October 2021

Publisher's Note: MDPI stays neutral with regard to jurisdictional claims in published maps and institutional affiliations.

Copyright: (c) 2021 by the authors. Licensee MDPI, Basel, Switzerland. This article is an open access article distributed under the terms and conditions of the Creative Commons Attribution (CC BY) license (https:// creativecommons.org/licenses/by/ $4.0 /)$.

\begin{abstract}
Aging heat treatment is the most commonly used strengthening method for $\mathrm{Al}-\mathrm{Mg}-\mathrm{Si}$ alloys since high-density precipitates will be formed to hinder the movement of dislocations. In the current work, room temperature cyclic deformation was attempted to strengthen the alloy. We compared tensile test results of aged samples and cyclically deformed samples. It was found that cyclically deformed samples can achieve similar strength and approximately twice the uniform elongation as the peak aged samples. The high density of dislocations and nanoclusters observed in the cyclically deformed samples is thought to be the main reason for strengthening. Different cyclic deformation conditions have been tried and their effects were discussed.
\end{abstract}

Keywords: Al-Mg-Si alloy; cyclic deformation; precipitation; mechanical properties; electron microscopy

\section{Introduction}

In order to mitigate the environmental burden of global warming, it is important to reduce greenhouse gas emissions such as carbon dioxide. In the automotive industry, weight reduction is required to improve fuel efficiency [1]. For aluminum alloys, the weight required to reach a certain strength is low because of their high specific strength [2]. Among them, $\mathrm{Al}-\mathrm{Mg}-\mathrm{Si}$ alloys have been widely considered due to their excellent weldability and good corrosion resistance [3].

The most widely used strengthening method for heat-treatable $\mathrm{Al}$ alloys such as $\mathrm{Al}-$ $\mathrm{Mg}-\mathrm{Si}$ alloys is artificial aging. A supersaturated solid solution (SSSS) can form precipitate phases in the matrix during aging, which hinder the movement of dislocations and thus increase the material strength $[4,5]$. The precipitation sequence in $\mathrm{Al}-\mathrm{Mg}-\mathrm{Si}$ alloys is shown below [5-11]: phases

SSSS $\rightarrow \mathrm{Mg} /$ Si clusters $\rightarrow$ Guinier Preston (GP) zones $\rightarrow \beta^{\prime \prime}$ phases $\rightarrow \beta^{\prime}$ phases $\rightarrow \beta$

Supersaturated solute atoms (Mg and $\mathrm{Si}$ ) leave the solution to form $\mathrm{Mg} / \mathrm{Si}$ clusters at the initial stage of aging [12]. Then, the highly-coherent, needle-shaped GP zones and $\beta^{\prime \prime}$ phases are formed as the main hardening precipitates at the peak hardness condition [13]. The $\beta^{\prime \prime}$ phase aligning along $<100>\mathrm{Al}$ directions has a monoclinic structure with the composition $\mathrm{Mg}_{5} \mathrm{Si}_{6}$ [14]. Further aging causes the $\beta^{\prime \prime}$ phase to thicken into the rod-shaped $\beta^{\prime}$ phase with the hexagonal structure [15]. Finally, the equilibrium $\beta$ phase appears at the over-aged stage with a cubic structure and composition of $\mathrm{Mg}_{2} \mathrm{Si}$ [14]. 
The aging temperature has a significant effect on nucleation and growth. In an appropriate temperature range, the lower the temperature, the greater the driving force for nucleation to form high-density precipitation nuclei, and the lower the atomic diffusivity requiring a longer aging time for growth [16]. It should be noted that when the aging temperature is near room temperature (natural aging), the formed cluster cannot further transform into the $\beta^{\prime \prime}$ phase. In order to distinguish it from the cluster formed during aging at $100{ }^{\circ} \mathrm{C}$ or more, which can normally transform into the $\beta^{\prime \prime}$ phase, the former and latter clusters are called cluster 1 and cluster 2, respectively [17-19]. Cluster 1 formed at room temperature dissolves at temperatures above $473 \mathrm{~K}$, so solution heat treatment (SHT) can be applied to eliminate the effects of natural aging [17].

There have been many reports on the influence of plastic deformation on the precipitation process [16,20-23]. As a representative work, the cyclic strengthening (CS) method proposed by Sun et al. introduces dislocations and accelerates the diffusion of solute atoms to form nanoclusters by applying periodic, reciprocating plastic deformation, thereby greatly improving the strength [16]. Cyclic strengthening has become an interesting and hot research topic of great significance. According to recent reports, cyclic deformation can also improve the fatigue performance of Al alloys [24] and even strengthen the non-heattreatable Al-Mg alloys by forming clusters [25].

In this study, we investigated the effect of cyclic deformation on mechanical properties in an extruded $6082 \mathrm{Al}$ alloy and examined the industrial outlook by comparing it with traditional artificial aging heat treatment. Microstructures of cyclically deformed samples were observed by transmission electron microscopy (TEM) to elucidate the strengthening mechanism. Finally, the strengthening effect of cyclic deformation under different conditions was discussed.

\section{Materials and Methods}

\subsection{Materials and Treatments}

The chemical composition of the studied aluminum alloy 6082 is given in Table 1 in weight and atomic percent. The material was supplied by Norsk Hydro (Sunndalsøra, Norway). The alloy was cast as $\varnothing 203$ billets and homogenized at $575^{\circ} \mathrm{C}$ for $2 \mathrm{~h}$ and $15 \mathrm{~min}$. It was further extruded as round profiles and stored at room temperature (RT) or naturally aged (NA) for 5 years.

Table 1. Chemical composition of the studied 6082 aluminum alloy.

\begin{tabular}{cccccccc}
\hline AA6082 & Si & Mg & Fe & Cu & Cr & Mn & Al \\
\hline at. \% & 1.16 & 0.84 & 0.12 & 0.03 & 0.09 & 0.30 & Bal. \\
wt. $\%$ & 1.20 & 0.75 & 0.24 & 0.08 & 0.18 & 0.60 & Bal. \\
\hline
\end{tabular}

The samples were classified into heat-treated and cyclically deformed. The heattreated samples include the raw NA samples (naturally aged at RT for 5 years), WQ (waterquenched) samples (solution heat-treated at $560{ }^{\circ} \mathrm{C}$ for $10 \mathrm{~min}$ followed by water quenching to RT), NA + AA (artificial aged), and WQ + AA samples (NA and WQ samples followed by artificial aging). The artificial aging was conducted at $180{ }^{\circ} \mathrm{C}$ for $4 \mathrm{~h}$, corresponding to the peak aging (T6) condition of this alloy [26,27], to induce a high number density of precipitates. Their treatment histories were summarized in Table 2.

Table 2. Treatment histories of various samples.

\begin{tabular}{ll}
\hline Samples & Treatment History \\
\hline NA & Extruded + NA for 5 years \\
WQ & Extruded + NA for 5 years + SHT \\
NA + AA & Extruded + NA for 5 years + AA at $180^{\circ} \mathrm{C}$ for $4 \mathrm{~h}$ \\
WQ + AA & Extruded + NA for 5 years + SHT + AA at $180{ }^{\circ} \mathrm{C}$ for $4 \mathrm{~h}$ \\
CS & Extruded + NA for 5 years + SHT + CS \\
\hline
\end{tabular}


The geometry of cyclically deformed samples is shown in Figure 1 . They were first subjected to solution heat treatment to dissolve the precipitates formed during the longtime natural aging. Immediately afterward, we used the Gleeble 3500 (Norsk Hydro, Sunndalsøra, Norway) to apply strain-controlled cyclic deformation on the sample to cause back and forth movement at room temperature as shown in Figure 2. Both edge sides of the sample were fixed by the Gleeble machine and the deformation was controlled by the movement of the Gleeble machine. We assume the deformation was contributed by the parallel part $(12 \mathrm{~mm})$ in the middle of the sample to calculate the strain amplitude. The default loading history in each cycle is shown in Figure 2a, with the strain ratio (also stress ratio) of -1 and the frequency of $0.2 \mathrm{~Hz}$. Figure $2 \mathrm{~b}$ shows the cyclic strengthening profile of the CS sample with the final loading stress of $335 \mathrm{MPa}$ as an example. It was totally carried out for 400 cycles in $2000 \mathrm{~s}$ under step strain control. The corresponding applied strain history is shown in Figure 2c, the strain amplitude was gradually increased from $0.9 \%$ to $1.6 \%$ with the step increase of $0.1 \%$ every 50 cycles.

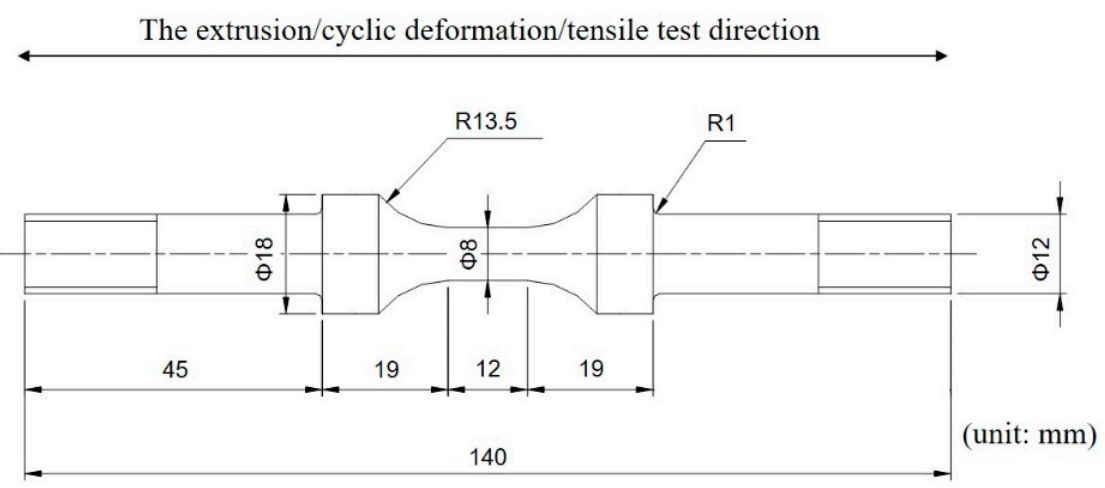

Figure 1. Sample geometry for cyclic strengthening process. The extrusion direction, cyclic deformation direction, and tensile test direction are all parallel as marked.
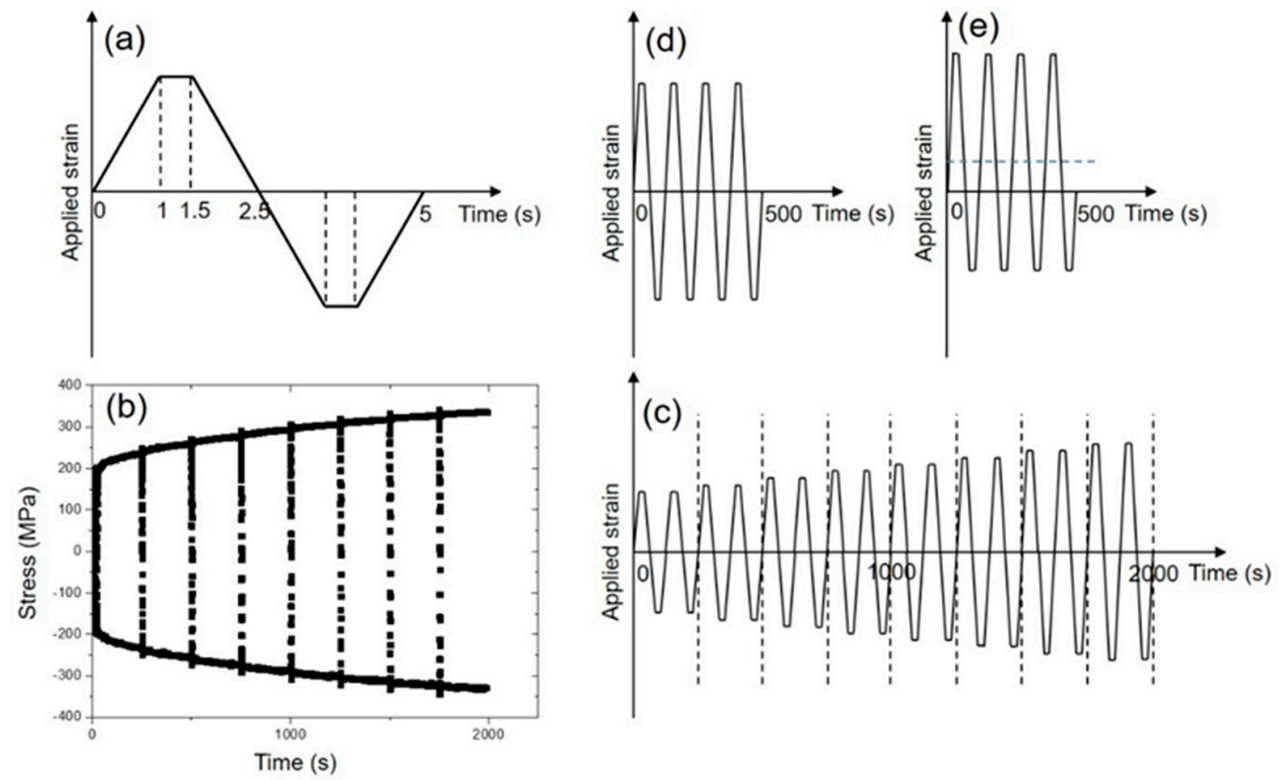

Figure 2. The schematic diagram of the cyclic deformation. (a) The standard applied alternating strain history in a single cycle. (b) Cyclic strengthening profile during the entire cyclic deformation from 0 to $2000 \mathrm{~s}$ under the step strain control. (c) The applied strain history corresponding to (b), divided into several steps marked by the black dashed line. (d) The applied strain history under constant strain control. (e) The applied strain history under constant strain control with a high tensile/compression ratio. Note that each cycle in (c-e) represents 25 cycles in the actual experiment. 
Besides step strain control, constant strain control was also tested in the current work. The strain amplitude of $0.6 \%$ and $1.5 \%$ was applied and kept the same from the first cycle until the end (100 cycles) for the standard constant strain control as shown in Figure $2 \mathrm{~d}$. The applied strain ranges from $-1.1 \%$ to $1.9 \%$ (keep the strain amplitude to be $1.5 \%$ for comparison) was designed for constant strain control with a higher tensile/compression ratio as shown in Figure 2e. Their differences will be discussed later.

\subsection{Tensile Tests}

Tensile tests were carried out on both the heat-treated and cyclically deformed samples using a Zwick/Roell Z100 (Zwick Roell, Ulm, Germany) at RT. The strain rate was $2.5 \times 10^{-4} \mathrm{~s}^{-1}$ until yield point and $6.7 \times 10^{-3} \mathrm{~s}^{-1}$ after yield point. Due to the limited number of samples, three specimens for WQ + AA and step strain-controlled CS conditions, two specimens for NA, NA + AA and constant strain-controlled CS (1.5\%), one specimen for constant strain-controlled CS with the applied strain of $0.6 \%$ and $-1.1 \% \sim 1.9 \%$ were tested. Note that the extrusion direction, cyclic deformation direction, and tensile test direction are all parallel to each other.

The time between SHT and subsequent procedures (such as AA and CS) were kept as short as possible, and the samples were stored in a freezer at $-40{ }^{\circ} \mathrm{C}$ before tensile tests (given 20 min to warm back to RT) and microstructural observations to avoid the influence of natural aging.

\subsection{Transmission Electron Microscopy}

TEM specimens were cut perpendicular to the cyclic deformation direction from the $12 \mathrm{~mm}$ parallel part of the specimen shown in Figure 1. They were ground down to around $100 \mu \mathrm{m}$ thickness and punched into $3 \mathrm{~mm}$ diameter discs. Then, the discs were electropolished until perforation using a Struers TenuPol-5 machine (Struers, Ballerup, Denmark) with the electrolyte (1/3 nitric acid and 2/3 methanol) kept between $243 \mathrm{~K}$ and $253 \mathrm{~K}$. To reduce the amount of contamination, all specimens were plasma cleaned in a Fischione 1020 Plasma Cleaner (E.A. Fischione Instruments, Inc., Export, PA, USA) for 3 min before the TEM observations.

The microstructures of the cyclically deformed samples (prior to the tensile test) were investigated by TEM using two microscopes, a JEOL 2100F (JEOL Ltd., Tokyo, Japan) and a double aberration corrected JEOL ARM 200F (JEOL Ltd., Tokyo, Japan) both operating at $200 \mathrm{kV}$. High angle annular dark-field scanning TEM (HAADF-STEM) images were acquired with a detector collection angle of 48.21-206.4 mrad and a convergence semiangle of $27.42 \mathrm{mrad}$. The 2100F was equipped with an Oxford EDS (Oxford Instruments, Abingdon, UK) and the ARM had a Centurio Large angle SDD-EDS. For all studies the electron beam was parallel to $<001>\mathrm{Al}$.

The column contrast in some images was enhanced by using a circular bandpass mask applied to the respective fast Fourier transform (FFT), to remove spatial frequencies (noise) in real space below $0.15 \mathrm{~nm}$, and an inverse FFT (IFFT) was performed on the masked area.

\section{Results and Discussion}

3.1. Mechanical Properties of Heat-Treated Samples and Cyclically Strengthened Samples

Engineering stress strain curves of the alloys subjected to heat treatments and cyclic deformations are shown in Figure 3. 

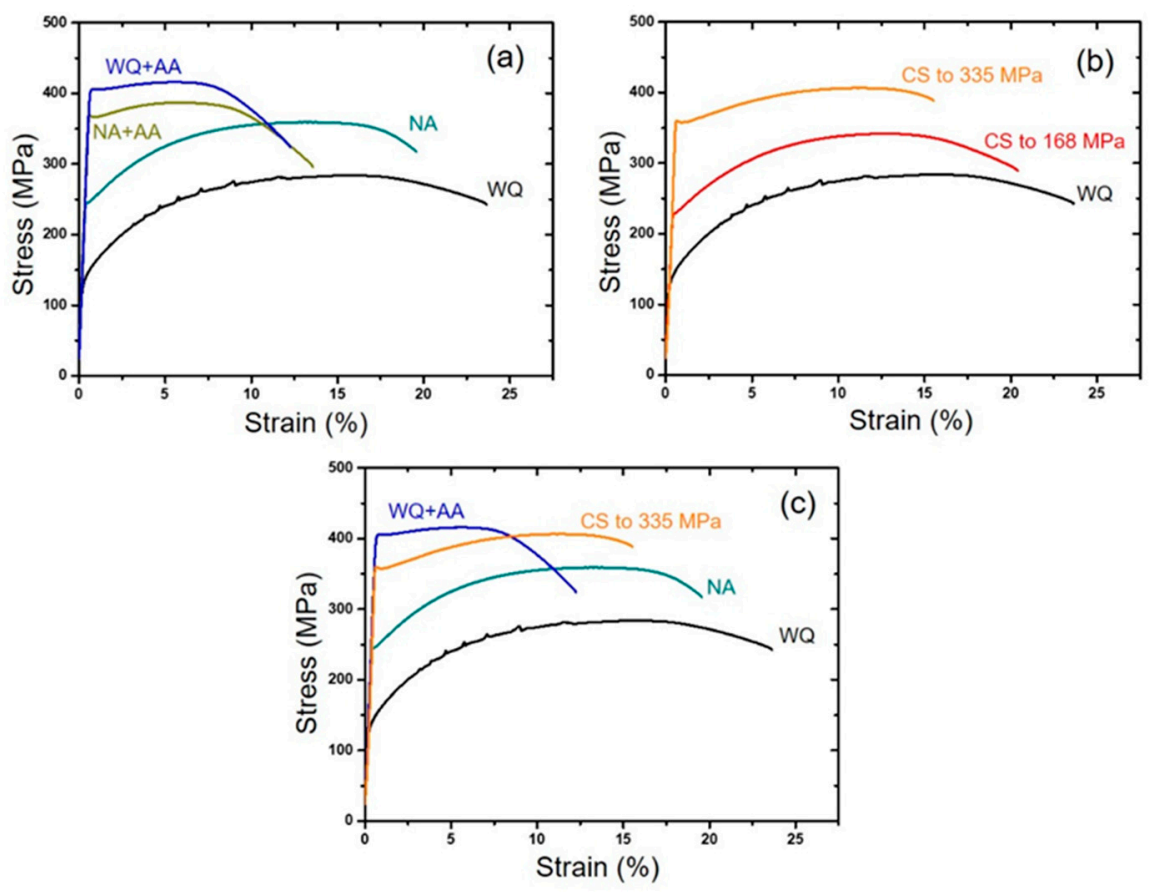

Figure 3. Tensile properties of alloys subjected to heat treatments and cyclic deformations. Engineering stress-strain curves of (a) heat-treated samples (WQ: water-quenched; NA: naturally aged; AA: artificially aged) and (b) cyclically deformed samples (CS: cyclically strengthened). (c) The comparison between heat-treated and cyclically deformed samples.

\subsubsection{Heat-Treated Samples}

Figure 3a shows the stress-strain curves of heat-treated samples under different conditions. For the WQ sample, all the existing precipitates are dissolved into the matrix during solution heat treatment, and a supersaturated solid solution is formed after water quenching, resulting in high ductility but low strength. After aging at $180^{\circ} \mathrm{C}$ for $4 \mathrm{~h}$ (WQ + AA), the main strengthening $\beta^{\prime \prime}$ phase will be formed, leading to the highest strength at the expense of ductility.

For the precipitation in NA samples, the driving force for nucleation is great while the diffusivity for growth is low, which results in the formation of uniformly distributed high-density nanoclusters. Therefore, the NA sample has a good strength and ductility combination. If the more aging time is given, the material will continue to follow the trend of increasing strength and decreasing ductility [28]. After natural aging for 5 years, even if artificial aging is performed, the existing dominant cluster 1 cannot transform into the $\beta^{\prime \prime}$ phase. However, the residual solute atoms will form cluster 2 and then transform into the strengthening $\beta^{\prime \prime}$ phase during artificial aging, causing strength increase and ductility decline.

It is worth mentioning that serrations in the stress-strain curve are associated with the strengthening and weakening caused by solute atoms pinning dislocation and dislocation escaping, respectively $[29,30]$. Therefore, this phenomenon is most conspicuous in the WQ sample, and it will be weakened when solute atoms in the matrix segregate into clusters or form precipitates after aging.

\subsubsection{Cyclically Strengthened Samples}

The tensile properties of solution heat-treated samples with various amplitudes of cyclic deformation are shown in Figure 3b. Compared with the WQ condition, as long as the sample undergoes plastic deformation, dislocations will be generated to contribute to strength. The yield stress (YS) and ultimate tensile strength (UTS) of the CS sample with a strain amplitude of $0.6 \%$ measured from tensile tests are 229 and $342 \mathrm{MPa}$, respectively. As the cyclic strain amplitude increases up to $1.6 \%$, the corresponding YS and UTS achieve 
a maximum at 359 and $406 \mathrm{MPa}$, respectively. If the cyclic strain amplitude continues to increase, there will be cracks on the sample surface, leading to premature fracture.

It is found that the cyclic strain amplitude is positively correlated to the YS and UTS and negatively correlated to the elongation. Moreover, as the strain amplitude increases, more dislocations will be introduced into the sample, resulting in a decrease in the work hardening effect (the difference between YS and UTS) during the tensile test. In short, tailored properties of advanced $\mathrm{Al}$ alloys can be designed according to the strain amplitude of cyclic deformation.

\subsubsection{Comparison between Aging and Cyclic Strengthening Method}

There is no doubt that cyclic deformation, natural and artificial aging are all effective ways to strengthen the alloy as shown in Figure 3c. In this section, we compare CS with NA and $W Q+A A$ from the viewpoint of experimental conditions and achieved mechanical properties. The data are summarized in Table 3.

Table 3. Summary of experimental conditions and achieved tensile properties of NA, WQ + AA and CS (up to $1.6 \%$ ).

\begin{tabular}{cccccc}
\hline Conditions & $\begin{array}{c}\text { Duration } \\
(\mathbf{k s})\end{array}$ & $\begin{array}{c}\text { Temperature } \\
\mathbf{( K )}\end{array}$ & $\begin{array}{c}\text { Uniform } \\
\text { Elongation (\%) }\end{array}$ & YS (MPa) & UTS (MPa) \\
\hline NA & 157680 & 298 & $13.4 \pm 0.1$ & $244 \pm 2$ & $358 \pm 2$ \\
WQ + AA & 14.4 & 458 & $5.4 \pm 0.4$ & $405 \pm 5$ & $416 \pm 3$ \\
CS & 2.0 & 298 & $11.4 \pm 0.2$ & $359 \pm 15$ & $406 \pm 4$ \\
\hline
\end{tabular}

(1) Comparison between CS and NA.

To strengthen the material, CS only needs approximately $30 \mathrm{~min}$ compared to several years of NA. If we use CS to replace NA, the uniform elongation will only drop from $13.4 \%$ to $11.4 \%$, while strength will rise significantly from 358 to $406 \mathrm{MPa}$. CS can also be regarded as the enhanced state on the extension line from WQ to NA, which means NA may also realize a strengthening effect similar to CS if given long enough aging time. The required NA time is roughly estimated to be several decades, which should be more than 100,000 times that of CS.

(2) Comparison between $\mathrm{CS}$ and $\mathrm{WQ}+\mathrm{AA}$.

Compared to $\mathrm{WQ}+\mathrm{AA}$, which requires not only high-temperature heat treatment but also a relatively long holding time, CS just needs one-seventh of the time and can be completed at room temperature. Meanwhile, CS can obtain an excellent uniform elongation more than twice that of WQ + AA and a high enough UTS which is only $2.5 \%$ less than that of WQ+ AA.

In summary, CS is an effective method to achieve excellent mechanical properties in industrial applications. In principle, the production efficiency can be evidently improved since CS can greatly save time. However, there is a shortcoming that the shape of CS samples is limited. If this disadvantage can be solved or alleviated by the development of advanced processing devices, it might be possible to achieve large-scale use of CS in the future.

\subsection{Transmission Electron Microscopy (TEM) Observation}

The microstructure of the CS samples (up to 1.6\%) was observed in TEM. As shown in Figure $4 \mathrm{a}$, a large number of dislocation lines and well-distributed fine dislocation loops were observed by low-angle annular dark-field STEM (LAADF-STEM). Some dislocation lines were tangled with each other, while some were pinned by the dispersoids. These dispersoids were confirmed to contain Mn by electron dispersive spectroscopy (EDS), the details are shown in the Supplementary Materials (Figure S1 and Table S1). Dispersoids form and grow during the homogenization treatment and will not dissolve during solution heat treatment [31,32]. 

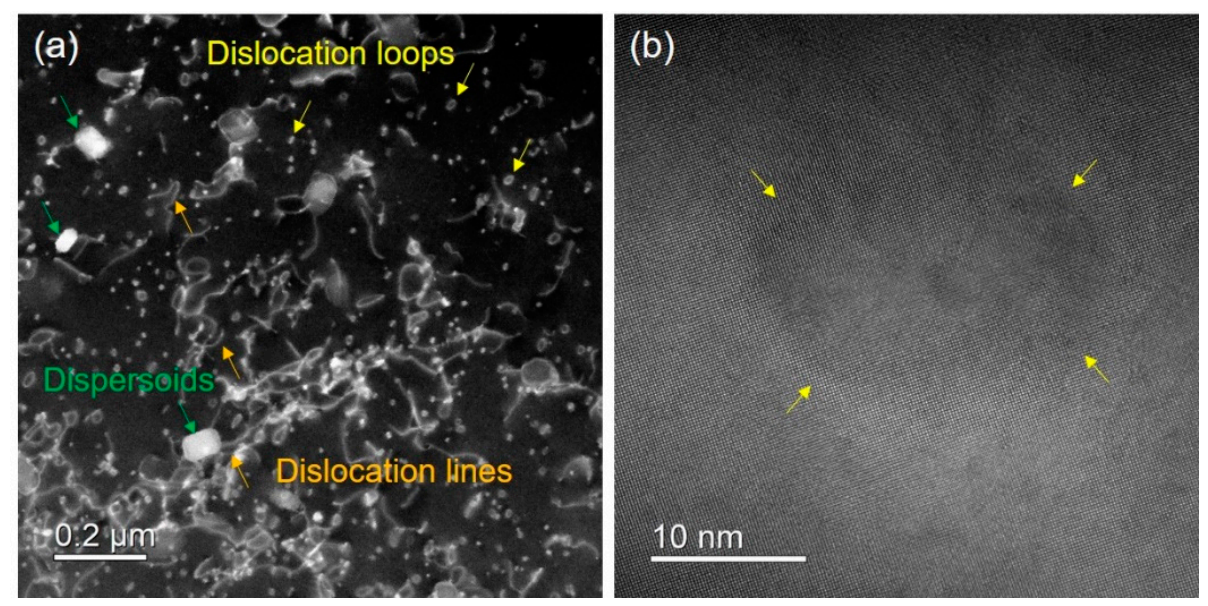

Figure 4. (a) Low-angle annular dark-field scanning transmission electron microscopy (LAADFSTEM) image showing dislocation lines and loops as well as dispersoids. (b) High-angle annular dark-field STEM (HAADF-STEM) image showing a dislocation loop at the center.

HAADF-STEM was used to obtain images with atomic resolution [33]. The morphology of a dislocation loop was shown in Figure $4 \mathrm{~b}$. Dislocation loops are formed by the agglomeration of vacancies generated by dragging dislocation jogs during the CS process [16]. The general size of the dislocation loops in the CS samples was between a few to tens of nanometers in diameter.

The presence of dislocations generates a stress field, and the solute atoms tend to move to the dislocation lines to offset the stress field caused by the size difference between $\mathrm{Al}$ and solute atoms. The direct evidence of $\mathrm{Cu}$ aggregation on an edge dislocation was successfully observed as shown in Figure 5a. There is an edge dislocation with bright spots (atomic columns) on its extra half-plane of atoms. The Burgers vector is determined through the Burgers loop around the dislocation line. Since HAADF-STEM shows Z contrast, the high-brightness atomic columns result from the aggregation of $\mathrm{Cu}$ atoms with a high atomic number [34,35]. This is consistent with the tendency of $\mathrm{Cu}$ atoms to aggregate on the extra half-plane of atoms subjected to compressive stress because of its smaller radius compared to $\mathrm{Al}$ [36]. In the same way, $\mathrm{Mg}$ atoms with a larger radius tend to occupy positions subjected to tensile stress. However, it is very challenging to differentiate between $\mathrm{Mg}$ and $\mathrm{Al}$ atoms in HAADF-STEM images due to their close atomic numbers, so we cannot clearly distinguish $\mathrm{Mg}$ and $\mathrm{Al}$ atoms here.
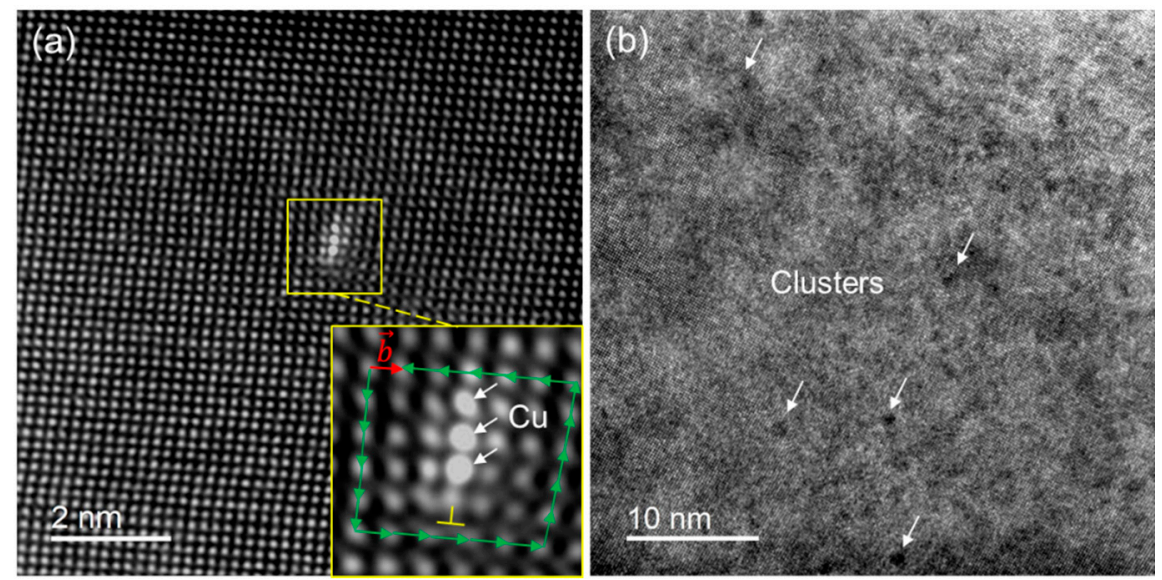

Figure 5. (a) Fast Fourier transform (FFT) filtered HAADF-STEM image showing Cu segregation on an edge dislocation. (b) FFT filtered high-resolution TEM (HRTEM) image showing well distributed high density of clusters. 
Both the short-circuit diffusion effect of dislocations and the vacancies produced by the dragging of dislocation jogs can accelerate the aggregation of solute atoms to form clusters [37,38]. The high-density clusters captured by high-resolution TEM (HRTEM) imaging are shown in Figure 5b. Since the free solute atoms have aggregated to form clusters, the serration in the CS sample is weakened as shown in Figure 3b.

Compared with uniformly distributed dislocations and clusters formed during CS, the relatively large $\beta$ " phase precipitates obtained during aging are more likely to cause stress concentration which leads to necking of the tensile specimen. Therefore, it can be inferred that the high density of dislocations and clusters are the main reasons for both the high strength and ductility of the CS samples.

\subsection{Effect of Cyclic Deformation Parameters on the Mechanical Properties}

The effects of frequency and strain amplitude of cyclic deformation on the mechanical properties have been studied [39]. Cyclic strengthening shows frequency independence and a positive correlation of strain amplitude. However, the effects of parameters such as loading methods and tensile/compression ratio have not been systematically investigated and will be discussed in this section.

\subsubsection{Constant or Step Control}

The tensile results of various samples are summarized in a uniform elongation-UTS chart, shown in Figure 6. The black and blue points represent WQ and WQ + AA samples, respectively. The blue dashed arrow represents reference properties achieved by artificial aging.

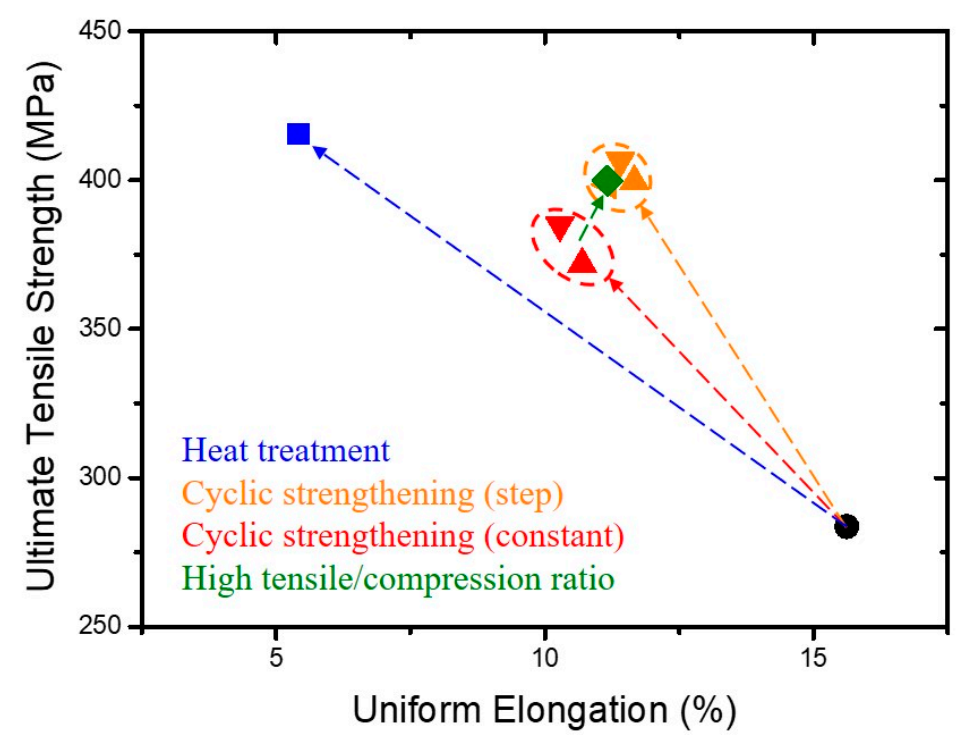

Figure 6. Summary of uniform elongation and ultimate tensile strength of both heat-treated and cyclically deformed samples with various conditions.

After CS, all the points are above the blue dashed line (on the upper right side), which indicates that CS can achieve a better strength-ductility combination than artificial aging. Moreover, the orange points (step controlled) are located at the upper right side of the red points (constant controlled), suggesting that step control is the more effective method. We consider the reason to be that the constant control method introduces a large number of dislocations at the beginning, causing entanglement between them, which is not favorable to the dislocation movement. Therefore, fewer vacancies are generated to help the formation of clusters. 


\subsubsection{Tensile/Compression Ratio}

In Section 3.1.2 we mentioned that if the cyclic strain amplitude is even larger, cracks will occur on the surface, resulting in a fast fracture. Through experimental observations, we speculate that the cracks are initiated mainly during the compression process. Therefore, we adjusted the tensile/compression ratio to a higher value based on constant control. As seen in Figure 6, the tensile property (green point) successfully broke through the red region, and ended with a final loading stress $326 \mathrm{MPa}$, even less than the maximum loading stress of $332 \mathrm{MPa}$ used for normal constant control.

Through a series of experiments, it was learned that factors such as strain amplitude, control method, and tensile/compression ratio can affect the results of CS. Part of our ongoing work is to improve the mechanical properties by adjusting other parameters of CS experiments and combining CS with aging.

\section{Conclusions}

The mechanical properties and microstructure of cyclically deformed samples were investigated. Compared with the conventional aging heat treatment, the cyclic strengthening method can achieve a similar ultimate tensile strength (406 MPa) and two times higher uniform elongation (5.4\% to $11.4 \%$ ) at room temperature within $2 \mathrm{ks}$. The high density of dislocation lines, uniformly distributed nano-sized dislocation loops, and nanoclusters are responsible for the cyclic strengthening. The step strain control and high tensile/compression ratio lead to better mechanical properties.

Supplementary Materials: The following are available online at https:/ /www.mdpi.com/article/10 $.3390 /$ met11111735/s1, Figure S1: TEM image showing the presence of dispersoids in the AQ sample. Observation direction is parallel to $<001>\mathrm{Al}$, Table S1: Composition of dispersoids calculated from EDS results.

Author Contributions: Conceptualization and methodology, X.C., E.A.M., R.H. and E.K.; formal analysis, X.C., E.A.M., J.K.S., C.D.M., R.H. and E.K.; investigation, X.C., J.K.S. and E.A.M.; writingoriginal draft preparation, X.C.; writing-review and editing, E.A.M., J.K.S., M.O., C.D.M., R.H. and E.K.; visualization, X.C.; supervision, E.K. All authors have read and agreed to the published version of the manuscript.

Funding: The authors acknowledge the INTPART project "Norwegian-Japanese Aluminum Alloy Research and Education Collaboration- phase II" (NFR: 287965) funded by the Norwegian Research Council (NFR) for establishing the collaborations to write this article. This research was also partially supported by the Grant for Integrated Frontier Study, The Light Metals Educational Foundation, Inc., and the SumAl project (NFR: 294933) from the Norwegian Research Council. The (S)TEM work was carried out on the NORTEM infrastructure (NFR: 197405) at the TEM Gemini Center, Trondheim, Norway.

Institutional Review Board Statement: Not applicable.

Informed Consent Statement: Not applicable.

Data Availability Statement: The raw/processed data required to reproduce these findings cannot be shared at this time as the data also form part of an ongoing study.

Acknowledgments: The authors are thankful to Terje Iveland and Ola Andersen at Hydro Sunndal for their contribution to Gleeble- and mechanical testing.

Conflicts of Interest: The authors declare no conflict of interest.

\section{References}

1. Hirsch, J. Aluminium in Innovative Light-Weight Car Design. Mater. Trans. 2011, 52, 818-824. [CrossRef]

2. Burger, G.; Gupta, A.; Jeffrey, P.; Lloyd, D. Microstructural control of aluminum sheet used in automotive applications. Mater. Charact. 1995, 35, 23-39. [CrossRef]

3. Miller, W.; Zhuang, L.; Bottema, J.; Wittebrood, A.; De Smet, P.; Haszler, A.; Vieregge, A. Recent development in aluminium alloys for the automotive industry. Mater. Sci. Eng. A 2000, 280, 37-49. [CrossRef] 
4. Gupta, A.; Lloyd, D.; Court, S. Precipitation hardening in Al-Mg-Si alloys with and without excess Si. Mater. Sci. Eng. A 2001, 316, 11-17. [CrossRef]

5. Murayama, M.; Hono, K. Pre-precipitate clusters and precipitation processes in Al-Mg-Si alloys. Acta Mater. 1999, 47, 1537-1548. [CrossRef]

6. Starink, M.J.; Van Mourik, P. A calorimetric study of precipitation in an Al-Cu alloy with silicon particles. Met. Mater. Trans. A 1991, 22, 665-674. [CrossRef]

7. Edwards, G.; Stiller, K.; Dunlop, G.; Couper, M. The precipitation sequence in Al-Mg-Si alloys. Acta Mater. 1998, 46, 3893-3904. [CrossRef]

8. Polmear, I.; StJohn, D.; Nie, J.-F.; Qian, M. Light Alloys: Metallurgy of the Light Metals; Butterworth-Heinemann: Oxford, UK, 2017.

9. Matsuda, K.; Sakaguchi, Y.; Miyata, Y.; Uetani, Y.; Sato, T.; Kamio, A.; Ikeno, S. Precipitation sequence of various kinds of metastable phases in Al-1.0mass\% $\mathrm{Mg}_{2} \mathrm{Si}-0.4 \mathrm{mass} \% \mathrm{Si}$ alloy. J. Mater. Sci. 2000, 35, 179-189. [CrossRef]

10. Fang, X.; Song, M.; Li, K.; Du, Y. Precipitation sequence of an aged Al-Mg-Si alloy. J. Min. Met. Sect. B Met. 2010, 46, 171-180. [CrossRef]

11. Miao, W.; Laughlin, D. Precipitation hardening in aluminum alloy 6022. Scr. Mater. 1999, 40, 873-878. [CrossRef]

12. Edwards, G.; Stiller, K.; Dunlop, G. APFIM investigation of fine-scale precipitation in aluminium alloy 6061. Appl. Surf. Sci. 1994, 76-77, 219-225. [CrossRef]

13. Saito, T.; Marioara, C.D.; Andersen, S.J.; Lefebvre, W.; Holmestad, R. Aberration-corrected HAADF-STEM investigations of precipitate structures in Al-Mg-Si alloys with low $\mathrm{Cu}$ additions. Philos. Mag. 2014, 94, 520-531. [CrossRef]

14. Andersen, S.J.; Zandbergen, H.; Jansen, J.; Træholt, C.; Tundal, U.; Reiso, O. The crystal structure of the $\beta^{\prime \prime}$ phase in Al-Mg-Si alloys. Acta Mater. 1998, 46, 3283-3298. [CrossRef]

15. Jacobs, M.H. The structure of the metastable precipitates formed during ageing of an Al-Mg-Si alloy. Philos. Mag. 1972, 26, 1-13. [CrossRef]

16. Sun, W.; Zhu, Y.; Marceau, R.; Wang, L.; Zhang, Q.; Gao, X.; Hutchinson, C. Precipitation strengthening of aluminum alloys by room-temperature cyclic plasticity. Science 2019, 363, 972-975. [CrossRef]

17. Serizawa, A.; Hirosawa, S.; Sato, T. 3DAP Characterization and Thermal Stability of Nano-Scale Clusters in Al-Mg-Si Alloys. Mater. Sci. Forum 2006, 519-521, 245-250. [CrossRef]

18. Serizawa, A.; Hirosawa, S.; Sato, T. Three-Dimensional Atom Probe Characterization of Nanoclusters Responsible for Multistep Aging Behavior of an Al-Mg-Si Alloy. Met. Mater. Trans. A 2008, 39, 243-251. [CrossRef]

19. Serizawa, A.; Sato, T.; Poole, W.J. The characterization of dislocation-nanocluster interactions in Al-Mg-Si (-Cu/Ag) alloys. Philos. Mag. Lett. 2010, 90, 279-287. [CrossRef]

20. Hutchinson, C.R.; De Geuser, F.; Deschamps, A. Dynamic room temperature precipitation during cyclic deformation of an Al-Zn-Mg-Cu alloy. In ICAA13 Pittsburgh; Springer International Publishing: Cham, Switzerland, 2012; pp. $1101-1106$.

21. Deschamps, A.; Fribourg, G.; Bréchet, Y.; Chemin, J.; Hutchinson, C. In situ evaluation of dynamic precipitation during plastic straining of an Al-Zn-Mg-Cu alloy. Acta Mater. 2012, 60, 1905-1916. [CrossRef]

22. Chen, X.; Marioara, C.D.; Andersen, S.J.; Friis, J.; Lervik, A.; Holmestad, R.; Kobayashi, E. Precipitation processes and structural evolutions of various GPB zones and two types of S phases in a cold-rolled Al-Mg-Cu alloy. Mater. Des. 2021, $199,109425$. [CrossRef]

23. Chen, X.; Kim, D.; Minho, O.; Marioara, C.D.; Andersen, S.J.; Lervik, A.; Holmestad, R.; Kobayashi, E. Effect of pre-deformation on age-hardening behaviors in an Al-Mg-Cu alloy. Mater. Sci. Eng. A 2021, 820, 141557. [CrossRef]

24. Zhang, Q.; Zhu, Y.; Gao, X.; Wu, Y.; Hutchinson, C. Training high-strength aluminum alloys to withstand fatigue. Nat. Commun. 2020, 11, 5198. [CrossRef]

25. Wenwen, S.; Zhu, Y.; Marceau, R.K.W.; Jiang, L.; Wang, L.; Gao, X.; Zhang, Q.; Hutchinson, C. A Pronounced Hardening Re-sponse in Non-Heat-Treatable Al-Mg Based 5xxx Aluminum Alloys. SSRN Electron. J. 2019, 1-7. [CrossRef]

26. Angella, G.; Bassani, P.; Tuissi, A.; Vedani, M. Aging Behaviour and Mechanical Properties of a Solution Treated and ECAP Processed 6082 Alloy. Mater. Trans. 2004, 45, 2282-2287. [CrossRef]

27. Serrao, P.; Chiranth, B.P.; Vaz, N.; Fernandis, A.; Rao, P. Effect of Equal Chanel Angular Pressing and Age Hardening on the Hardness of Al-Mg-Si Alloy. Am. J. Mater. Sci. 2017, 7, 150-155. [CrossRef]

28. Weisz, T.; Warczok, P.; Ebner, T.; Falahati, A.; Kozeschnik, E. Simulation of Natural Aging in Al-Mg-Si Alloys. Mater. Sci. Forum 2015, 828-829, 468-473. [CrossRef]

29. Abbadi, M.; Hähner, P.; Zeghloul, A. On the characteristics of Portevin-Le Chatelier bands in aluminum alloy 5182 under stress-controlled and strain-controlled tensile testing. Mater. Sci. Eng. A 2002, 337, 194-201. [CrossRef]

30. Aboulfadl, H.; Deges, J.; Choi, P.; Raabe, D. Dynamic strain aging studied at the atomic scale. Acta Mater. 2015, 86, 34-42. [CrossRef]

31. Hu, R.; Ogura, T.; Tezuka, H.; Sato, T.; Liu, Q. Dispersoid Formation and Recrystallization Behavior in an Al-Mg-Si-Mn Alloy. J. Mater. Sci. Technol. 2010, 26, 237-243. [CrossRef]

32. Liu, C.; Azizi-Alizamini, H.; Parson, N.; Poole, W.; Du, Q. Microstructure evolution during homogenization of Al-Mg-Si-Mn-Fe alloys: Modelling and experimental results. Trans. Nonferr. Met. Soc. China 2017, 27, 747-753. [CrossRef]

33. Pennycook, S.J. The impact of STEM aberration correction on materials science. Ultramicroscopy 2017, 180, 22-33. [CrossRef] 
34. Treacy, M.M. Z Dependence of Electron Scattering by Single Atoms into Annular Dark-Field Detectors. Microsc. Microanal. 2011, 17, 847-858. [CrossRef] [PubMed]

35. Pennycook, S. Structure determination through Z-contrast microscopy. Adv. Imaging Electron Phys. 2002, 123, 173-206. [CrossRef]

36. Fleischer, R. Substitutional solution hardening. Acta Met. 1963, 11, 203-209. [CrossRef]

37. Shewmon, P.G. Diffusion in Solids; McGraw-Hill: New York, NY, USA, 1963.

38. Huang, J.; Xu, K.; Fan, Y.M.; Wang, J.F.; Zhang, J.C.; Ren, G.Q. Dislocation luminescence in GaN single crystals under nanoindentation. Nanoscale Res. Lett. 2014, 9, 649. [CrossRef] [PubMed]

39. Han, W.; Chen, Y.; Vinogradov, A.; Hutchinson, C. Dynamic precipitation during cyclic deformation of an underaged Al-Cu alloy. Mater. Sci. Eng. A 2011, 528, 7410-7416. [CrossRef] 